\title{
Design and Synthesis of New Cyclic Phosphazene Based Blue Light- Emitting Dendrimers
}

\author{
T. MA, C.J. JING \\ School of Chemical Engineering and Environment, Beijing Institute of Technology, Beijing 100081, China
}

\begin{abstract}
In order to obtain new emitting materials with an improved thermal stability and the luminescence efficiency, we designed a new type of cyclic phosphazene based blue light-emitting dendrimers, in which the rigid spherical cyclic phosphazene core is chemically bonded with the anthracene branches. Three synthesis routes has been studied for the preparation of the target molecule.
\end{abstract}

KEYWORD: Light-emitting dendrimers; cyclic phosphazene; anthracene; synthesis routes

\section{INSTRUCTION}

Organic light-emitting diodes (OLEDs) has drawn much intense research efforts since Tang[1]reported the first double layers devices in 1987, due to their characteristics, such as low driving voltage, high brightness, full-color emission, rapid response and self-emitting properties. In nowadays, OLEDs have been successfully applied in the fields of mobile phones, car stereos, digital cameras and white solidstate lighting.[2-9]

Light-emitting material is the key part of an OLED device. Although small molecular organic material or polymers as preferred candidates have been reported, the more extensive application of OLEDs in large-area and flexible devices is yet limited by the high cost, luminescence efficiency and lifetime.[10]

Dendrimers and oligomers, normally referring to the molecular weights lying in between 1000-10,000 dalton, can combine the advantaged properties of both small molecules and polymers [11]. In this work, we designed a new type of blue light-emitting material cyclic phosphazene based anthracene dendrimer. As shown in Fig. 1, the target molecule combines the unique rigid spherical Cyclic phosphazene core[12] and a number of anthracene branches. The former possesses of excellent thermal stability and the latter is regarded as highly efficiency material in photoluminescence and electroluminescence behaviors. [13]



Figure 1. The Target Molecule

\section{RESULTS AND DISCUSSION}

There are two issues should be taking into our consideration in the synthesis of unique dendrimer. The first is to figure out the suitable Suzuki reaction for this kind of dendrimer, and the second is to ensure all the functional groups attached to the core completely. Accordingly we designed three routes.

As shown in Fig.2, hexachlorotriphosphazene (1) reacts with 4-bromophenol to give the compound 2, which was then converted to compound 3 by the reaction with bis(pinacolato) diboron. Suzuki coupling reaction of the boron compound 3 with 9bromoanthracene formed the desired product in a very low yield of 3.3\%.[14] 


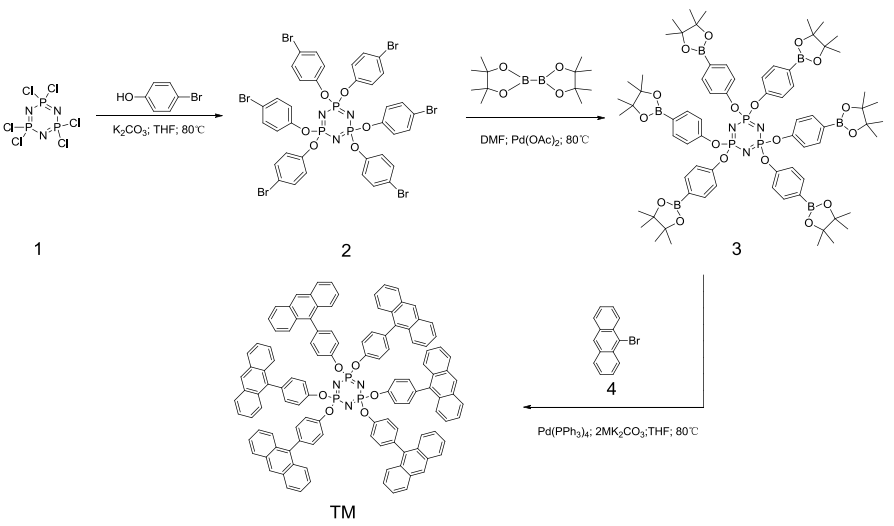

Figure 2. Synthesis Route 1

In order to improve the yield, anthracene boric acid of 9-anthraceneboronic acid (5) was prepared for Suzuki reaction instead of the boron compound described above. Reaction of 5 with 2 provided the desired product in a little higher yield of $5.3 \%$ (Fig.3) than that in the first route.

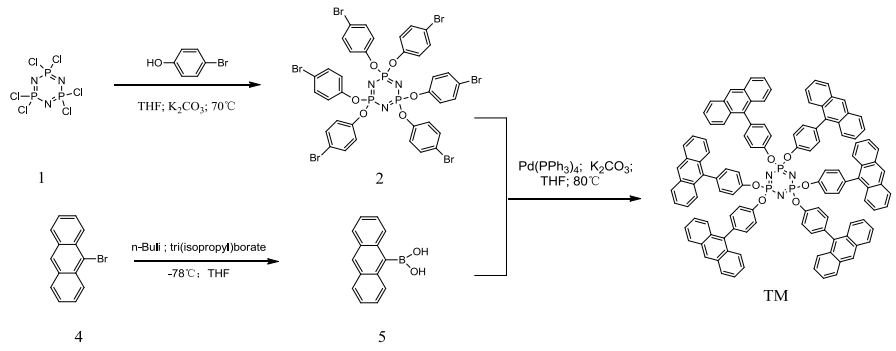

Figure 3. Synthesis Route 2

The low yield was ascribed to difficulties of the functional group in the attachment to the core structure. So we challenged a new strategy and designed the third route. Therefore, we tried a new synthetic strategy by which branch unit 6 would be first prepared with 4-bromophenol by Suzuki reaction, and then coupling of the branch with triphosphazene core would result in the desired product (Fig.4). However, the preparation of 6 was failed probably because the Suzuki reaction was interfered by the phenolic hydroxyl group. Further study by protection of the hydroxyl has been remained.



Figure 4. Synthesis Route 3

\section{CONCLUSIONS}

We design and synthesized a new kind of anthracene blue light-emitting dendrimers based cyclic triphosphazene. Three synthetic routes were testified. The product was obtained but the yield remains to be improved.

\section{ACKNOWLEDGEMENTS}

This work was supported by the National Natural Science Foundation of China (No 51103012, No 21272025), the Research Fund for the Doctoral Program of Higher Education of China (No 20111101110042), and the Beijing Natural Science Foundation (No 7102091).

\section{REFERENCES}

[1] C. W. Tang and S. Van Slyke, 1987, Appl. Phys. Lett., 51:913.

[2] L. S. Huang and C. H. Chen, 2002, Mater. Sci. Eng., 39:143.

[3] C. W. Tang, S. A. Van Slyke and C. H. Chen, 1989, J. Appl. Phys., 65:3610.

[4] J. H. Burroughes, D. D. C. Bradley, A. R. Brown, R. N. Marks, K. Mackay, R. H. Friend, P. L. Burn and A. B. Homes, 1990, Nature, 347:539.

[5] M. A. Baldo, D. F. O'Brien, Y. You, A. Shoustikov, S. Sibley, M. E. Thompson and S. R. Forest, 1998, Nature, 395:151.

[6] W. -Y. Wong and C. -L. Ho, 2009, J. Mater. Chem., 19:4457.

[7] S. Chen, L. Deng, J. Xie, L. Peng, L. Xie, Q. Fan and W. Huang, 2010, Adv. Mater, 22:5227.

[8] K. Walzer, B. Maennig, M. Pfeiffer and K. Leo, 2007, Chem. Rev., 107:1233.

[9] B. W. D'Andrade and S. R. Forrest, 2004, Adv. Mater., $16: 1585$.

[10] Jinhai Huang, Jian-Hua Su and He Tian, 2012, J. Mater. Chem., 22:10977

[11] Henk J. Bolink, Eva Barea, Ruben D. Costa, Eugenio Coronado, Sundarraj Sudhakar, Changgua Zhen, Alan Sellinger, 2008, Organic Electronics, 9:155.

[12] Sundarraj Sudhakar and Alan Sellinger, 2006, Macromol. Rapid Commun., 27:247.

[13] J. Huang, J. -H. Su, X. Li, M. -K. Lam, K. -M. Fuang, H. -H. Fan, K. -W. Cheah, C. H. Chen and H. Tian, 2011, J. Mater. Chem., 21:2957.

[14] Henk J. Bolink, Sonsoles Garcia Santamaria, Sundarraj Sudhakar, Changgua Zhen and Alan Sellinger, 2008, Chem. Commun., 5:618.

[15] Nicholas E. Leadbeater and Maria Marco, 2002, Org. Lett., 4:2973.

[16] 